\title{
Axillary Arch May Affect Axillary Lymphadenectomy
}

\author{
Hasan Karanlik ${ }^{\mathrm{a}}$ Alisan Fathalizadeh ${ }^{\mathrm{b}}$ Burak Ilhan ${ }^{\mathrm{a}} \quad$ Kursat Serin $^{\mathrm{c}}$ Sidika Kurula $^{\mathrm{a}}$
}

aSurgical Oncology Unit, Institute of Oncology, Istanbul University, Capa, Turkey

${ }^{b}$ Michigan State University College of Human Medicine, East Lansing, Michigan, USA

'Department of Surgery, Istanbul Medical Faculty, Istanbul University, Capa, Turkey

\section{Keywords}

Langer's axillary arch - Axillary lymphadenectomy .

Anatomic anomaly of the axilla

\section{Summary}

Background: The aim of this study was to identify the axillopectoral muscle anomaly commonly known as Langer's axillary arch, and to understand its importance in surgical procedures of the axilla. Patients and Methods: Between 2009 and 2011, 758 patients underwent sentinel lymph node biopsy, axillary dissection, or both. Patients with Langer's axillary arch were identified and assessed retrospectively. The decision to cut or preserve the axillary arch was made based on clinical judgment, and patients were followed-up accordingly to monitor for adverse outcomes. Results: Of the 758 patients who underwent axillary procedures, 9 (1.2\%) were found to have a Langer's axillary arch. In 2 patients the arch was cut, and in 7 patients it was preserved. No adverse outcomes were identified in any of the patients upon follow-up. Conclusion: Langer's axillary arch is a unique anatomic anomaly of the axillary region that may be problematic due to the potential risks of lymphedema and vascular or nerve compression. It is important for surgeons and radiologists alike to be aware of this anatomic variation in order to properly identify it and respond appropriately based on clinical judgment, and to complete close follow-up of the patient due to the potentially increased risk of adverse outcomes.

\section{Schlüsselwörter \\ Langerscher Achselbogen · Axilläre Lymphadenektomie . Anatomische Anomalie der Axilla}

\section{Zusammenfassung}

Hintergrund: Ziel dieser Studie war es, die axillopektorale Muskelanomalie bekannt als Langerscher Achselbogen zu identifizieren und ein Verständnis potentieller Auswirkungen dieser Struktur auf chirurgische Eingriffe an der Axilla zu gewinnen. Patienten und Methoden: Zwischen 2009 and 2011 wurde bei 758 Patientinnen eine Sentinelknotenbiopsie, eine axilläre Lymphknotendissektion oder beides durchgeführt. Patientinnen mit einem Langerschen Achselbogen wurden identifiziert und retrospektiv bewertet. Die Entscheidung, den Achselbogen zu durchtrennen bzw. zu erhalten, wurde basierend auf der klinischen Gesamtlage getroffen, und die Patientinnen wurden entsprechend weiterverfolgt und hinsichtlich eines nachteiligen Behandlungsausgangs nachbeobachtet. Ergebnisse: Von den 758 Patientinnen, bei denen ein Eingriff an der Axilla vorgenommen wurde, hatten 9 (1,2\%) einen Langerschen Achselbogen. Bei 2 Patientinnen wurde die Struktur durchtrennt, bei 7 Patientinnen wurde sie erhalten. Keine der Patientinnen zeigte einen nachteiligen Behandlungsausgang in der Nachbeobachtung. Schlussfolgerung: Der Langersche Achselbogen ist eine einzigartige anatomische Anomalie der Achselhöhle, die auf Grund des potentiellen Risikos der Lymphödementstehung bzw. Einklemmung von Gefäßen oder Nerven zu Problemen führen kann. Sowohl Chirurgen als auch Radiologen sollten sich dieser anatomischen Variation bewusst sein, um sie korrekt zu identifizieren und basierend auf der klinischen Situation entsprechend auf sie reagieren zu können. Der Nachbeobachtung kommt ebenfalls große Wichtigkeit zu, da das Risiko eines nachteiligen Ausgangs potentiell erhöht ist.

\section{KARGER \\ Fax +497614520714 \\ Information@Karger.com}

www.karger.com (c) 2013 S. Karger GmbH, Freiburg

$1661-3791 / 13 / 0086-0424 \$ 38.00 / 0$

Accessible online at:

www.karger.com/brc
Hasan Karanlik, M.D.

stanbul University, Institute of Oncology

Surgical Oncology Unit

Capa 34193, Istanbul, Turkey

hasankaranlik@yahoo.com 


\section{Introduction}

Sentinel lymph node biopsy (SLNB) and axillary lymphadenectomy are common surgical procedures particularly for breast surgeons [1]. Knowledge of the surgical anatomy of the axilla is of great importance for many common procedures including sentinel lymph node biopsies, axillary lymphadenectomies, mastectomies, and breast reconstruction procedures. When carrying out an axillary lymphadenectomy, the boundaries of the surgical procedure form a triangle and are formed by the lateral border of the pectoralis major muscle, the axillary vein at its superior end, the border of the latissimus dorsi and the serratus anterior muscle at the base. This axillary region generally contains the neurovascular bundle, many lymph nodes and vessels, and lateral branches of the axillary nerves [1]. Additionally, several anatomic variations may be present, and awareness of such variations and their features is essential for completing axillary surgery with better outcomes [2]. The most common anatomical anomaly in the axillary region is the presence of an axillopectoral muscle, also known as Langer's axillary arch. The axillary arch is believed to be an embryological remnant of the panniculus carnosus found in mammals, although it may occur as a variation of the apectoralis quartus, intermedius, and sternalis. This muscle group is highly developed in lower mammals and forms the pectoral muscle group [3-5]. The axillary arch muscle has variable nerve supply but may be innervated by the lateral pectoral or thoracodorsal nerve to name a few variations $[3,6]$. The blood supply to the axillary arch is generally from the lateral thoracic vessels [3]. Langer's axillary arch presents with many anatomic variations. This anomaly may be found in $7-8 \%$ of the population with a prevalence range of $7-27 \%$ and higher prevalences noted in cadaveric dissections $[1,3,4,7,8]$. The most common variation of Langer's axillary arch passes over the neurovascular bundle in the axillary arch and extends from the anterior border of the latissimus dorsi to the posterior surface of the tendon of the pectoralis major muscle $[1,3$, $4,8]$. The arch generally originates from the latissimus dorsi or occasionally the pectoralis major, and may insert in a variety of locations including the pectoralis major or pectoralis minor, coracobrachialis, short head of the biceps brachii, teres major, long head of the triceps brachii, coracoid process, axillary or brachial fascia, coracoid process, or medial epicondyle of the humerus $[3,5]$. The main purpose of this study was to properly identify the axillopectoral muscle commonly known as Langer's axillary arch, and to understand its importance in surgical procedures such as axillary lymphadenectomy and sentinel lymph node biopsy.

\section{Patients and Methods}

Between February 4th, 2009 and September 14th, 2011758 patients underwent an axillary procedure (SLNB, axillary dissection, or both) at the University of Istanbul Institute of Oncology. The procedures were completed by a breast surgeon in the case of breast cancer patients and by a plastic surgeon in the case of melanoma patients. During the course of these procedures, 9 patients were identified to have a unique anatomic anomaly in the form of an axillopectoral muscle, also known as an axillary arch, based on relevant surgical anatomic landmarks. Preservation or cutting of the axillary arch was completed based on appropriate clinical a

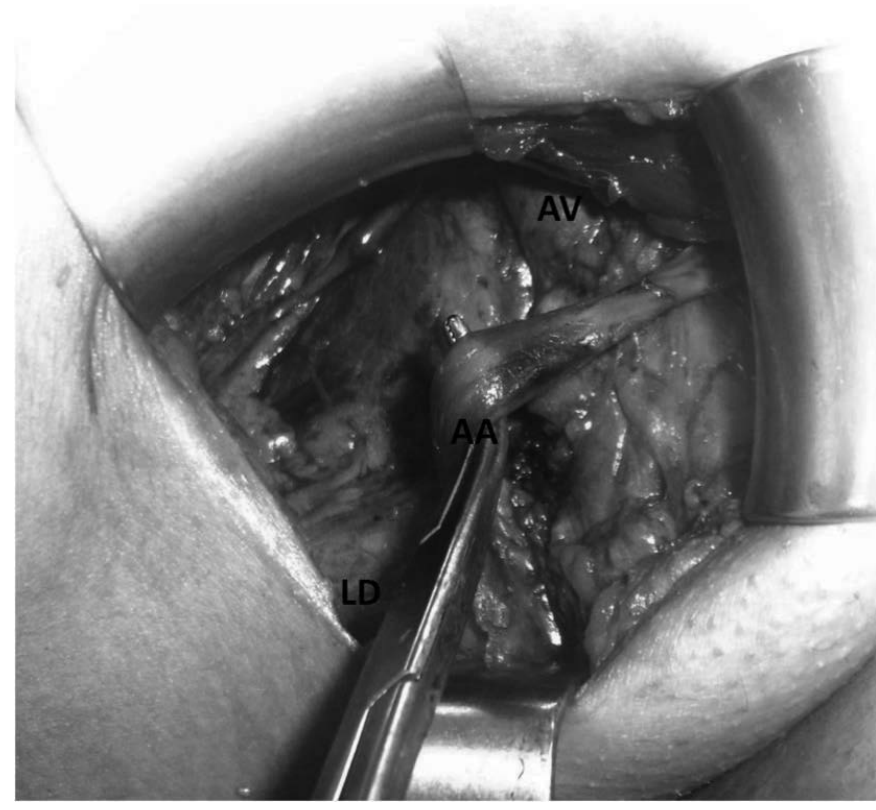

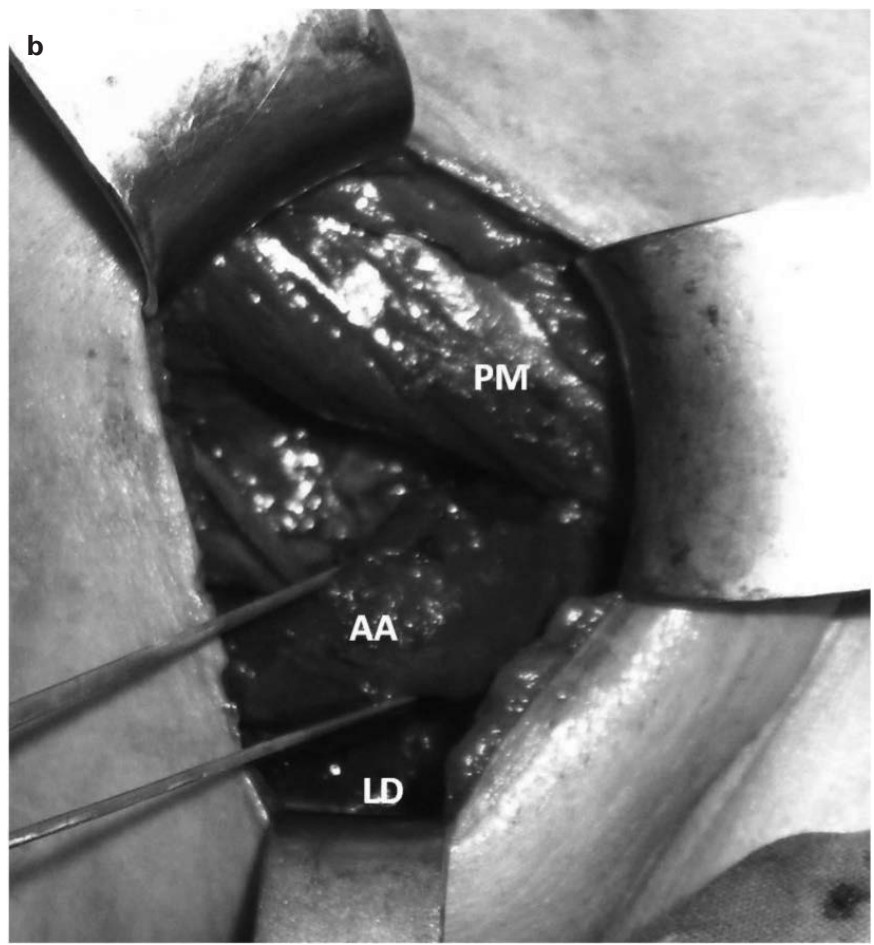

Fig. 1 a, b. Langer's axillary arch ( $\mathrm{AV}=$ axillary vein; $\mathrm{AA}=$ axillary arch; $\mathrm{LD}=$ latissimus dorsi; $\mathrm{PM}=$ pectoralis major). 
Table 1. Patient characteristics

\begin{tabular}{|c|c|c|c|c|c|c|c|c|c|c|c|c|}
\hline Patient & $\begin{array}{l}\text { Age, } \\
\text { years }\end{array}$ & Sex & $\begin{array}{l}\text { Cancer } \\
\text { type }\end{array}$ & Side & $\begin{array}{l}\text { Surgery for } \\
\text { primary tumor }\end{array}$ & $\begin{array}{l}\text { Axillary } \\
\text { procedure }\end{array}$ & $\begin{array}{l}\text { Follow-up, } \\
\text { months }\end{array}$ & $\begin{array}{l}\text { Tumor } \\
\text { size, } \mathrm{mm}\end{array}$ & $\begin{array}{l}\text { Met } \\
\text { LNs, n }\end{array}$ & $\begin{array}{l}\text { Total } \\
\text { LNs, n }\end{array}$ & BMI & $\begin{array}{l}\text { Axillary } \\
\operatorname{arch} T x\end{array}$ \\
\hline 1 & 50 & M & melanoma & left & left axilla & SLNB & 35.4 & 14.0 & 0 & 2 & 26.83 & cut \\
\hline 2 & 72 & M & melanoma & left & left axilla & SLNB & 31.7 & 4.3 & 0 & 2 & 26.79 & preserved \\
\hline 3 & 70 & $\mathrm{~F}$ & breast & right & mastectomy & $\mathrm{AD}$ & 31.5 & 30.0 & 0 & 18 & 20.76 & preserved \\
\hline 4 & 28 & M & melanoma & right & right axilla & SLNB + AD & 28.9 & 3.4 & 1 & 17 & 24.62 & preserved \\
\hline 5 & 48 & $\mathrm{~F}$ & breast & right & mastectomy & SLNB + AD & 28.1 & 80.0 & 3 & 10 & 20.55 & preserved \\
\hline 6 & 42 & M & melanoma & left & left axilla & SLNB & 24.1 & 1.1 & 0 & 2 & 26.42 & preserved \\
\hline 7 & 39 & $\mathrm{~F}$ & breast & right & lumpectomy & SLNB + AD & 12.0 & 20.0 & 5 & 15 & 22.49 & preserved \\
\hline 8 & 45 & $\mathrm{~F}$ & breast & left & lumpectomy & SLNB + AD & 5.8 & 30.0 & 3 & 18 & 23.03 & cut \\
\hline 9 & 55 & $\mathrm{~F}$ & breast & right & lumpectomy & SLNB & 3.9 & 20.0 & 2 & 13 & 24.98 & preserved \\
\hline
\end{tabular}

$\mathrm{M}=$ Male; $\mathrm{F}$ = female; $\mathrm{SLNB}$ = sentinel lymph node biopsy; $\mathrm{AD}$ = axillary dissection;

Met $=$ metastasized $; \mathrm{LNs}=$ lymph nodes; $\mathrm{BMI}=$ body mass index $; \mathrm{Tx}=$ treatment

judgment at the time of the procedure. The characteristics and data of these 9 patients were identified, and the patients were followed up to evaluate for potential adverse consequences of the procedure and for outcomes associated with preservation versus sacrifice of the axillary arch. Specifically, patients were evaluated in a follow-up clinical examination. Additionally, upper and lower arm measurements were evaluated the day following the axillary procedures and in further patient follow-up to monitor for lymphedema as one of the major potential complications. The clinical event rate was low, and thus no comparative statistics were completed.

\section{Results}

In the time period described, 758 axillary procedures were carried out. $395(52 \%)$ of these patients were breast cancer and 363 (48\%) melanoma patients. Of these, 9 (1.2\%) patients were identified to have an axillary arch. The frequency of axillary arch was $1.3 \%(5 / 395)$ in breast cancer patients and $1.1 \%(4 / 363)$ in melanoma patients. The distribution of the axillary arch among men and women was similar (1.3 and $1 \%)$. The mean age of identified patients was 49.9 years (range 28-72 years). The average body mass index was 24.1 (20.6-26.8). 4 male melanoma patients were identified and 5 female breast cancer patients. 4 patients underwent SLNB, 4 underwent SLNB plus axillary dissection, and 1 patient underwent axillary dissection only. Axillary arches were identified in the 9 patients; 2 of the arches were cut whereas 7 were preserved. Of the patients who had the axillary arch cut, 1 was a breast cancer patient and 1 was a melanoma patient. All of the identified axillary arches were found to extend from the lattisimus dorsi to the pectoralis major muscle (figs. 1 a and b). The average follow-up time was 22.4 months (range 3.935.4 months). Patient characteristics are summarized in table 1. Follow-up demonstrated no identifiable adverse consequences attributable to the presence of an axillary arch. In particular, no identified upper limb lymphedema, thoracic outlet syndrome, or axillary vein or nerve compression were noted. All of the patients had maintained the full range of mobility upon their follow-up clinical examination.

\section{Discussion}

As the most common anatomical anomaly in the axillary region, the axillopectoral muscle known as Langer's axillary arch is a key landmark that should be identifiable to surgeons and radiologists alike. The incidence of axillary arch identified in our patient population was $1.2 \%$, consistent with other clinical evaluations, yet less than the $7-8 \%$ identified in cadaveric studies. Anatomic studies demonstrate a 2-3-fold higher rate of identification of the axillary arch $[1,3,4,7,8]$. Whether the difference in surgical and anatomical incidence reflects a failure of reporting, recognition, or that sentinel nodes under an arch form only a small percentage, is not known. Sex differences, experience of the surgeon, and awareness of axillary arch anomaly probably contribute to the difficulty in discerning the true incidence. However, our data represents the work of 2 experienced surgeons in a single center. Also, this discrepancy may be largely attributed to the specific aim of cadaveric studies to identify such anatomic anomalies and the limitations of smaller axillary procedures such as SLNB where the anatomy of the axilla may not be fully identified.

As noted previously, the anatomic variations of Langer's axillary arch are manifold, and the presence or absence of this anatomical variation should be ascertained in every SLNB or dissection due to the possible complications that may result with this ectopic muscle [9]. Langer's axillary arch has been implicated in concealing level I lymph nodes in axillary dissection and thereby resulting in erroneous supra-axillary dissection $[3,4,6]$. Additionally, the risk of neurovascular compression leading to postoperative upper limb lymphedema and thoracic outlet syndrome has also been described [1-4, 7]. This compression has been noted particularly during abduction or external rotation of the arm $[1,7]$. Compression of the brachial plexus, particularly of the median nerve, and the contribution from the medial and lateral cords is a known risk $[2,4]$. With regards to hemodynamic compromise, 1 study noted no change in hemodynamic parameters in the arteries but compression of venous blood flow with compensatory increased blood velocity [7]. The axillary arch muscle also has 
been also associated with major thrombosis of the upper extremities [2]. Thus, awareness of the possible complications of an axillary arch muscle and the understanding that this muscle anomaly is not functionally significant demonstrate that this muscle group can be cut without any functional deficit [1].

Based on the described potential complications and the ease with which these complications may be avoided through simple dissection of the muscle group, early identification of the axillary arch muscle is important in clinical practice. 1 study described how 'radiologists' familiarity with the arch can improve their recognition of the muscular variant so that they can communicate appropriate clinical correlations to the referring physicians.' Although routine preoperative magnetic resonance imaging (MRI) for the evaluation of the arch is not a current recommendation, MRI may serve as a means to assess the anatomic correlations between the arch and lymph nodes and the brachial plexus [4]. Other options, such as the use of multi-detector row computed tomography have been employed as a means of diagnosing an axillary arch for preoperative and intraoperative planning and navigation of SLNB, whereby the undetected presence of an axillary arch has been described as a 'pitfall' [10]. Thus, the clinical significance of the presence of an axillary arch has been defined. Further investigations into possible imaging modalities for preoperative recognition of the arch are warranted.

All of the examples of the axillary arch identified in this study demonstrate the most common version of this anatomic variation, with the arch extending from the latissimus dorsi to the pectoralis major. The anatomic variations of the axillary arch are numerous, and the presence or absence of the muscle should be identified in every axillary procedure due to the potential complications that may result. The presence of an axillary arch may conceal the lateral level I lymph nodes, and thus identification of this anatomic variation is essential for surgeons to ensure appropriate axillary dissection. In the cases described in this study, the surgeons completing the procedures used their own clinical judgment in identifying whether they perceived the axillary arch as potentially problematic for the patient, resulting in the decision to preserve or cut the arch. No adverse consequences were identified among these described cases, and thus we support that it is important for surgeons to assert their clinical judgment in determining how to handle identified axillary arches. In such patients, particularly those in whom the axillary arch is preserved, it is particularly important to ensure adequate clinical follow-up to evaluate for potential adverse outcomes. Based on the aforementioned reasons, early recognition of an axillary arch is of great clinical importance.

\section{Disclosure Statement}

The authors state that there is no conflict of interest. No particular funding source was obtained for the development and conducting of this study.

\section{References}

$D_{1}$ Natsis K, Vlasis K, Totlis T, Paraskevas G, Noussios G, Skandalakis P, Koebki J: Abnormal muscles that may affect axillary lymphadenectomy: surgical anatomy. Breast Cancer Res Treat 2009; 120:77-82.

$\checkmark 2$ Pahwa S, Kumar A, Sharda VK, Pandove PK: Axillary arch: a unique entity. ANZ J Surg 2011; 81:752-3.

3 Bonastre V, Rodriguez-Niedenfuhr M, Choi D, Sanudo J: Coexistence of a pectoralis quartus muscle and an unusual axillary arch: case report and review. Clin Anat 2002;15:366-70.

4 Guy MS, Sandhu SK, Gowdy JM, Cartier CC, Adams JH: MRI of the axillary arch muscle: pre- valence, anatomic relations, and potential consequences. AJR 2010;196:52-7.

5 Ramanadham S, Kalthur SG, Pai SR: Unilateral axillary arch and variations in the axillary vein and intercostal nerves: a case report. Malaysian J Med Sci 2011;18:68-71.

6 Ridgway PF, Collins AM, McCready DR: The surgical importance of an axillary arch in sentinel node biopsy. Surg Radiol Anat 2011;33:147-9.

7 Provyn S, Balestra C, Delobel A, Wilputte F, Leduc O, Pouders C, Snoeck T: Are there hemodynamic implications related to an axillary arch?' Clin Anat 2011;24:964-7.
8 Keshtgar MRS, Saunders C, Ell PJ, Baum M: Langer's axillary arch in association with sentinel lymph node. Breast 1999;8:152-3.

9 Chêne G, Le Bouëdec G, Dauplat J: Arch and sentinel: surgical technique of sentinel node biopsy with the axillopectoral muscle.' Gynecol Obstet Fertil 2007;35:25-29.

10 Ando J, Kitamura T, Kuroki Y, Igarashi S: Preoperative diagnosis of the axillary arch with multidetector row computed tomography and the axillary arch in association with anatomical problems of sentinel lymph node biopsy. Breast Cancer 2010; 17:3-8. 